\title{
Synthesis, Spectral Characterization and Crystal Structure of 2-((3-Aminophenyl)(phenyl)methylene) hydrazinecarboxamide
}

\author{
Yi-Chen Chan ${ }^{1}$, Abdussalam Salhin Mohamed Ali ${ }^{1 *}$, Melati Khairuddean ${ }^{1}$, \\ Ching-Kheng Quah ${ }^{2}$
}

${ }^{1}$ School of Chemical Sciences, Universiti Sains Malaysia, Penang, Malaysia; ${ }^{2}$ X-ray Crystallography Unit, School of Physics, Universiti Sains Malaysia, Penang, Malaysia.

Email: *abdussalam@usm.my

Received March $3^{\text {rd }}, 2013$; revised April $7^{\text {th }}, 2013$; accepted April 14 $4^{\text {th }}, 2013$

Copyright (C) 2013 Yi-Chen Chan et al. This is an open access article distributed under the Creative Commons Attribution License, which permits unrestricted use, distribution, and reproduction in any medium, provided the original work is properly cited.

\begin{abstract}
A benzophenone substituted semicarbazone, 2-((3-aminophenyl)(phenyl)methylene)hydrazinecarboxamide (APHC) had been synthesized in good yield by the condensation of 3-aminobenzophenone and semicarbazide hydrochloride. The title compound was elucidated by elemental analysis (CHN), FTIR, ${ }^{1} \mathrm{H}$ and ${ }^{13} \mathrm{C}-\mathrm{NMR},{ }^{1} \mathrm{H}-{ }^{1} \mathrm{H}$ COSY, TGA and single crystal X-ray diffraction. The compound crystallized in the orthorhombic crystal system with space group of $P c c n, Z=$ 32, $V=10375.1$ (2) $\AA^{3}$, and lattice constants $a=12.3855$ (1) $\AA, b=34.5746$ (5) $\AA, c=24.2283$ (3) $\AA$ and $\gamma=\beta=\alpha=$ $90^{\circ}$. The molecular view shows that APHC contains four molecules of each species in the asymmetric unit, with similar geometries. However, there is no intramolecular hydrogen bond found in the crystal structure of the synthesized compound. X-ray diffraction also reveals that the molecule of the semicarbazone exists as a $Z$ isomer with respect to the $\mathrm{C}=\mathrm{N}$.
\end{abstract}

Keywords: Semicarbazone; Aminobenzophenone; Benzophenone; Hydrazone

\section{Introduction}

Semicarbazones are urea derivatives with versatile structural features having the general formula $R_{1} R_{2} \mathrm{C}=\mathrm{N}-$ $\mathrm{NH}-(\mathrm{CO})-\mathrm{NH}_{2}$ formally derive $\mathrm{d}$ by condensation of aldehyde or ketone with semicarbazide. In recent years a great number of studies have been devoted to the search for derivatives of semicarbazides and studied their chemical and structural properties due to their chemistry and potentially beneficial biological activities, such as anticonvulsant [1-2], antimicrobial [3-5], antioxidant [6], anticancer [7], etc. They are organic compounds that possess $\mathrm{C}=\mathrm{N}$ functional group and are considered as one of the important classes of Schiff base compounds parallel with their sulfur analog, thiosemicarbazones. Semicarbazones are among the most relevant nitrogen-oxygen donor ligands that provide potential binding sites for a wide variety of metal ions [8-10]. They usually react as chelating ligands with transition metal ions by bonding through the oxygen and the hydrazinic nitrogen atom. However, their coordination capacity is highly affected

\footnotetext{
"Corresponding author.
}

by the position of the chelating group present on the aldehyde or ketone part of the semicarbazone compound. In this paper, we report the synthesis, characterization and crystal structure of newly synthesized semicarbazone compound, namely as 2-((3-aminophenyl)(phenyl)methylene)hydrazinecarboxamide, APHC. Figure 1 displays the synthetic route of APHC.

\section{Experimental}

In the preparation of APHC, all the reagents were used as received. Melting point was determined by Stuart Scientific (UK) apparatus. Elemental analysis (CHN) was carried out on a Perkin Elmer Series II, 2400 analyzer. IR spectrum was recorded as $\mathrm{KBr}$ pellets on a Perkin Elmer System 2000 FTIR spectrophotometer in the wavenumber range of $4000-400 \mathrm{~cm}^{-1}$. NMR spectra were recorded on a Bruker Avance III $500 \mathrm{MHz}$ spectrometer in DMSO- $\mathrm{d}_{6}$ using tetramethylsilane as an internal standard. Thermogravimetric analysis (TGA) data was recorded by Mettler Toledo TS0801RO Sample Robot (TGA/SDTA$851^{\mathrm{e}}$ ), heating rate of $20^{\circ} \mathrm{C} / \mathrm{min}$ in the range of $30^{\circ} \mathrm{C}-$ 


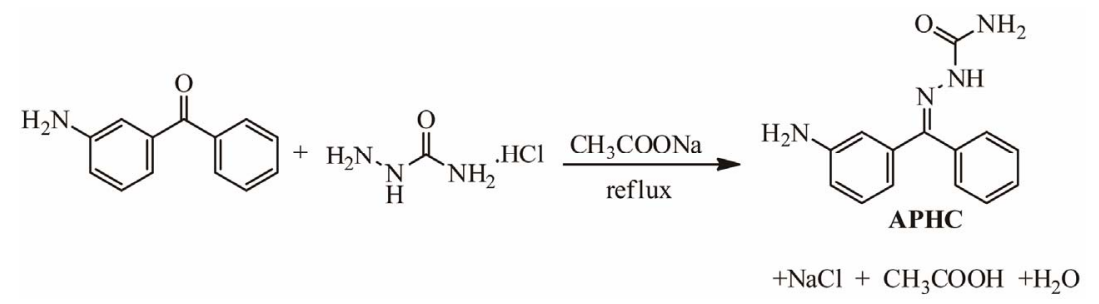

Figure 1. Synthetic pathway of APHC.

$900^{\circ} \mathrm{C}$ under nitrogen atmosphere.

\subsection{Synthesis of 2-((3-Aminophenyl)(phenyl) methylene)hydrazinecarboxamide, APHC}

A $5.5 \mathrm{~mL}$ ethanolic solution of 3-aminobenzophenone (3 mmol) was added dropwise to an aqueous solution of semicarbazide hydrochloride $(3 \mathrm{mmol})$ and sodium acetate $(4.5 \mathrm{mmol})$. The mixture was stirred well and refluxed till a clear solution was obtained. The solution was kept under controlled evaporation. After few days, brown crystals were formed. Single crystal of APHC suitable for X-ray crystallography was obtained after recrystallization from ethanol. Yield: $79 \%$. m.p.: $196^{\circ} \mathrm{C}-197^{\circ} \mathrm{C}$. Anal. Calcd for $\mathrm{C}_{14} \mathrm{H}_{14} \mathrm{~N}_{4} \mathrm{O}: \mathrm{C} 66.14, \mathrm{H}$ 5.51, N 22.05\%; found: C 66.10, H 5.57, N 22.02\%. Main IR bands (KBr, $\left.\mathrm{cm}^{-1}\right)$ : $3471(\mathrm{~m}), 3451(\mathrm{~m}), 3337(\mathrm{~m}), 3192(\mathrm{~m}), 1687(\mathrm{~s})$, 1629 (m), 1582 (s), 1494 (sh), 1450 (s), 1394 (m), 1328 (m), 1032 (w). ${ }^{1} \mathrm{H}-\mathrm{NMR} 500 \mathrm{MHz},\left(\mathrm{DMSO}-\mathrm{d}_{6}, \mathrm{ppm}\right): \delta$ $5.41\left(2 \mathrm{H}, \mathrm{s}, \mathrm{Ar}-\mathrm{NH}_{2}\right), 6.35$ - $6.36(1 \mathrm{H}, \mathrm{td}, \mathrm{H} 6), 6.40(1 \mathrm{H}$, $\left.\mathrm{s}, \mathrm{H}_{2}\right), 6.70\left(2 \mathrm{H}, \mathrm{s}, \mathrm{CONH}_{2}\right), 6.72-6.74(1 \mathrm{H}, \mathrm{ddd}, \mathrm{H} 4)$, 7.26 (1H, t, H5), 7.35 - 7.37 (3H, m, H10, H11, H12), 7.61 - 7.63 (2H, m, H9, H13), $7.67(1 \mathrm{H}, \mathrm{s}, \mathrm{NH}) .{ }^{13} \mathrm{C}$ NMR (ppm): $\delta 112.49,114.57,114.74,126.87,128.16$, 128.82, 130.32, 132.24, 136.99, $147.42(\mathrm{C}=\mathrm{N}), 149.87$ $\left(\mathrm{C}-\mathrm{NH}_{2}\right), 155.65(\mathrm{C}=\mathrm{O})$.

\subsection{X-Ray Structure Determination}

Crystals were placed in the cold stream of an Oxford Cyrosystems Cobra open-flow nitrogen cryostat [11] operating at 100.0 (1) K. Crystallographic data was collected using a Bruker SMART APEX II DUO CCD diffractometer [12]. The data were then reduced using SAINT [12] software. SADABS and SAINT software [12] were used for absorption correction and data reduction, respectively. The structure was refined by full-matrix least squares on $F^{2}$ and solved by direct methods using the SHELXTL [13] software package. N-bound H atoms were located in a difference Fourier map and refined freely $[\mathrm{N}-\mathrm{H}=0.79$ (2) - 1.08 (3) $\AA$ ]. The remaining hydrogen atoms were positioned geometrically $[\mathrm{C}-\mathrm{H}=0.95$ $\AA]$ and were refined using a riding model, with $U_{\text {iso }} \sim(\mathrm{H})$ $=1.2 U_{\text {eq }}(\mathrm{C})$. The crystal APHC was an inversion twin with a 0.180 (1):0.820 (1) domain ratio. The details of the crystal data and structure refinements are given in Table 1.
Table 1. Crystal and structure refinemental data of APHC.

\begin{tabular}{|c|c|}
\hline Compound & APHC \\
\hline Formula & $\mathrm{C}_{14} \mathrm{H}_{14} \mathrm{~N}_{4} \mathrm{O}$ \\
\hline Formula weight & 254.29 \\
\hline Color, shape & Brown; block \\
\hline Crystal system & Orthorhombic \\
\hline Space group & Pccn \\
\hline$Z$ & 32 \\
\hline Lattice constants & $\begin{array}{c}a=12.3855(1) \AA, b=34.5746(5) \AA \\
c=24.2283(3) \AA, \gamma=\beta=\alpha=90^{\circ}\end{array}$ \\
\hline Volume $\left(\AA^{3}\right)$ & $10375.1(2)$ \\
\hline $\mathrm{Dx}\left(\mathrm{Mg} \mathrm{m}^{-3}\right)$ & 1.302 \\
\hline$\mu\left(\mathrm{mm}^{-1}\right)$ & 0.09 \\
\hline$F(000)$ & 4288 \\
\hline$\theta$ range $\left({ }^{\circ}\right)$ & 2.4 to 29.0 \\
\hline$h, k, l$ & $-14 / 17,-48 / 42,-31 / 34$ \\
\hline Reflections collected & 86543 \\
\hline Reflections unique & 15195 \\
\hline$T_{\min } / T_{\max }$ & $0.965 / 0.980$ \\
\hline$R($ int $)$ & 0.057 \\
\hline Number of parameters & 765 \\
\hline Goodness of Fit & 1.07 \\
\hline Final $R$ index $[I>2 \sigma(I)]$ & 0.073 \\
\hline
\end{tabular}

\section{Results and Discussion}

\subsection{Description of the Crystal Structure}

The molecular view of APHC (Figure 2) shows that APHC contains four molecules of each species in the asymmetric unit, with similar geometries. In each molecule, the benzene rings make dihedral angle of 88.13 (11), 86.22 (10), 82.65 (11) and $78.22(11)^{\circ}$, respectively, indicating both rings are essentially perpendicular to each other. The selected bond lengths and bond angles are given in Table 2. There is no intramolecular hydrogen bond found in crystal structure of APHC. In the crystal packing (Figure 3), molecules are linked via intermolecular N-H $\cdots \mathrm{O}$ and $\mathrm{N}-\mathrm{H} \cdots \mathrm{N}$ hydrogen bonds (Table 3) into extended one-dimensional chains along [100]. Adjacent chains are cross-linked via further N-H $\cdots \mathrm{O}$ inter- 


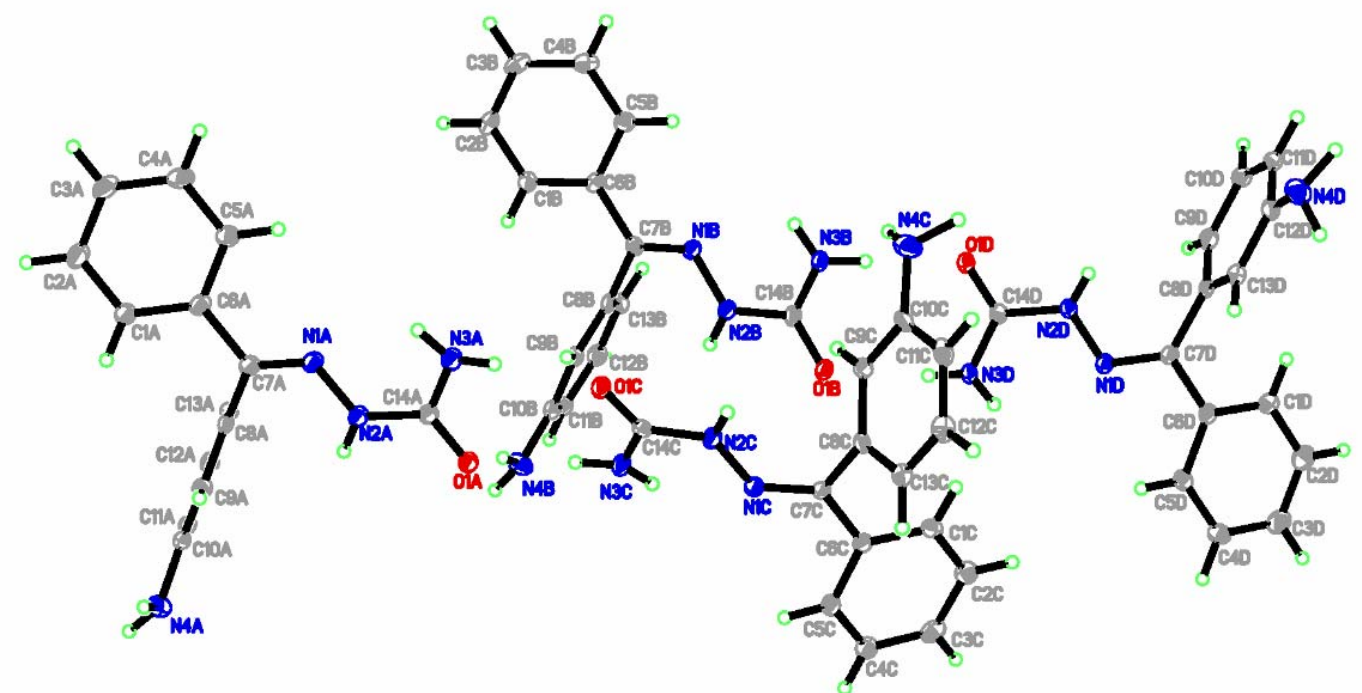

Figure 2. The molecular structures of APHC, showing $30 \%$ probability displacement ellipsoids for non-H atoms and the atom-numbering scheme.

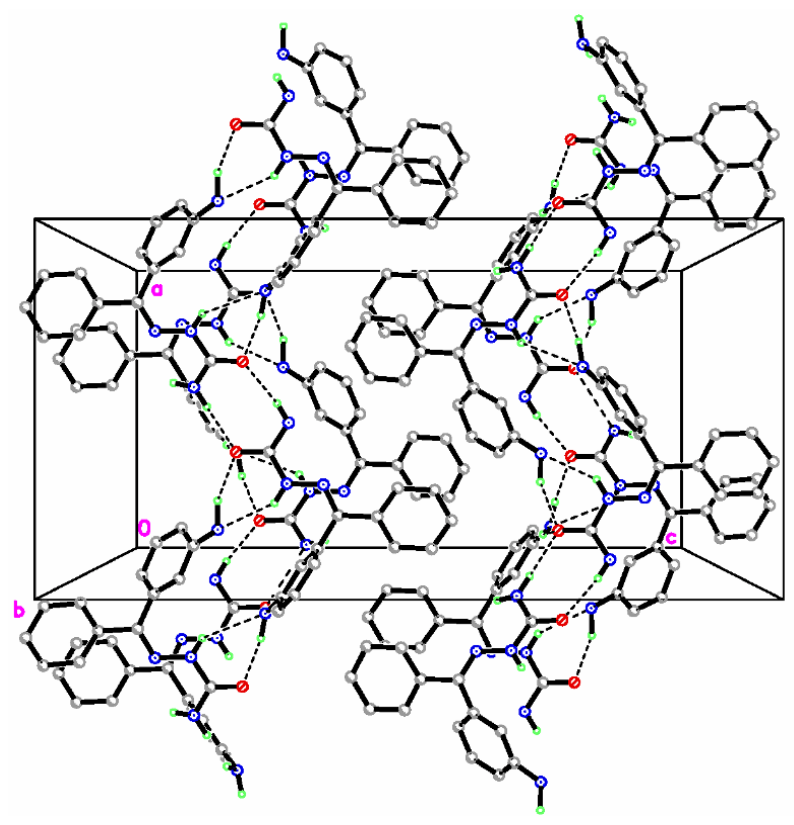

Figure 3. The crystal structures of APHC, viewed along the $b$ and $a$ axes, respectively.

Table 2. Selected bond lengths ( $\AA$ ) and bond angles ( ${ }^{\circ}$ ).

\begin{tabular}{cccc}
\hline Bond & Length & Bond & Angle \\
C6-C7 & $1.483(3)$ & C7-N1-N2 & $116.49(17)$ \\
C7-C8 & $1.500(3)$ & C14-N2-N1 & $120.55(17)$ \\
N1-C7 & $1.286(3)$ & N2-C14-N3 & $117.98(18)$ \\
N2-C14 & $1.362(3)$ & N1-C7-C6 & $117.50(18)$ \\
N3-C14 & $1.335(3)$ & N1-C7-C8 & $123.66(18)$ \\
O1-C14 & $1.251(2)$ & C6-C7-C8 & $118.67(17)$ \\
N1-N2 & $1.387(2)$ & O1-C14-N3 & $123.27(19)$ \\
& & O1-C14-N2 & $118.75(18)$ \\
\hline
\end{tabular}

actions into two-dimensional networks parallel to (001) plane. The crystal structure is further consolidated by $R_{2}^{2}(6)$ and $R_{2}^{2}(10)$ ring motifs [14].

\subsection{FT-IR Spectrum}

In the FT-IR spectrum of APHC, the N-H stretching vibrations of $\mathrm{NH}_{2}$ and $\mathrm{N}-\mathrm{H}$ groups are appeared as medium-intensity bands in the region of $3192-3471 \mathrm{~cm}^{-1}$. A strong absorption characteristic of $\mathrm{C}=\mathrm{O}$ stretching mode of an amide (amide I band) is observed at 1687 $\mathrm{cm}^{-1}$ while the $\delta(\mathrm{N}-\mathrm{H})$ (amide II band) is observed at $1450 \mathrm{~cm}^{-1}$ [15]. The $\mathrm{C}=\mathrm{N}$ stretching vibration of an azomethine group is attributed to an absorption at 1582 $\mathrm{cm}^{-1}[16]$ and the $v(\mathrm{~N}-\mathrm{N})$ band in APHC is assigned to the vibration at $1032 \mathrm{~cm}^{-1}$ [17].

\section{3. ${ }^{1} \mathrm{H}-\mathrm{NMR}$ Spectroscopy}

Figure 4 illustrates the ${ }^{1} \mathrm{H}-\mathrm{NMR}$ spectrum of APHC. Singlets at $\delta 5.41$ and $6.70 \mathrm{ppm}$ are assigned to the aromatic amine protons and the amide protons, respectively, whilst proton in the secondary amine - $\mathrm{NH}$ - group is assigned to a broad singlet at $\delta 7.67 \mathrm{ppm}$. The triplet of doublets at $\delta 6.35-6.36 \mathrm{ppm}$, triplet at $\delta 6.40 \mathrm{ppm}$, doublet of doublet of doublets at $\delta 6.72-6.74$ ppm and triplet at $\delta 7.26 \mathrm{ppm}$ are attributed to $\mathrm{H} 6, \mathrm{H} 2, \mathrm{H} 4$ and $\mathrm{H} 5$, respectively. $\mathrm{H} 2, \mathrm{H} 4$ and $\mathrm{H} 6$ are meta magnetically coupled to each other. At the same time, H4 is also coupled to H5 with a characteristic ortho coupling constant of 8 Hz. The same goes to the coupling between H6 and H5, where $\mathrm{H} 6$ is located at the ortho position towards H5. The aromatic protons $\mathrm{H} 10, \mathrm{H} 11$ and $\mathrm{H} 12$ are assigned to a multiplet at $\delta 7.35-7.37 \mathrm{ppm}$. On the other hand, H9 and $\mathrm{H} 13$ which are chemically equivalent are assigned to 
Table 3. Geometries of intermolecular hydrogen bonds in APHC.

\begin{tabular}{|c|c|c|c|c|}
\hline D-H $\cdots A$ & D-H/Å & $\mathbf{H} \cdots \mathbf{A} / \AA$ & $\mathbf{D} \cdots \mathbf{A} / \AA$ & 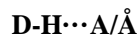 \\
\hline N3B-H3NB $\cdots$ O1D & $0.88(2)$ & $1.94(2)$ & $2.814(2)$ & $177(2)$ \\
\hline $\mathrm{N} 2 \mathrm{C}-\mathrm{H} 1 \mathrm{NC} \cdots \mathrm{N} 4 \mathrm{~A}$ & $0.89(2)$ & $2.61(2)$ & $3.347(3)$ & $141.5(19)$ \\
\hline N3D-H2ND $\cdots$ O1B & $0.80(2)$ & $2.04(2)$ & $2.838(2)$ & $172(3)$ \\
\hline N4A-H5NA $\cdots$ O1C & $0.98(3)$ & $2.01(3)$ & $2.970(3)$ & $165(3)$ \\
\hline N4B-H5NB $\cdots$ O1A ${ }^{i}$ & $0.92(3)$ & $2.04(3)$ & $2.956(3)$ & $170(3)$ \\
\hline N3A-H3NA $\cdots$ O1C & $0.88(3)$ & $2.11(3)$ & $2.979(2)$ & $171(3)$ \\
\hline N4D-H5ND $\cdots \mathrm{O}^{\mathrm{ii}}$ & $1.01(4)$ & $2.03(4)$ & $3.024(3)$ & $167(3)$ \\
\hline N3C-H3NC $\cdots$ O1 $A^{i}$ & $0.89(3)$ & $2.05(3)$ & $2.931(2)$ & $173(3)$ \\
\hline N2A-H1NA $\cdots$ N4C & $0.87(2)$ & $2.35(2)$ & $3.127(3)$ & $148(2)$ \\
\hline $\mathrm{N} 3 \mathrm{C}-\mathrm{H} 2 \mathrm{NC} \cdots \mathrm{N} 4 \mathrm{D}^{\mathrm{i}}$ & $0.83(3)$ & $2.58(3)$ & $3.373(3)$ & $160(2)$ \\
\hline $\mathrm{N} 4 \mathrm{C}-\mathrm{H} 5 \mathrm{NC} \cdots \mathrm{O} 1 \mathrm{~A}$ & $1.08(4)$ & $1.97(4)$ & $3.001(3)$ & $159(3)$ \\
\hline N4B-H4NB $\cdots$ O1D ${ }^{\mathrm{i}}$ & $0.95(3)$ & $1.98(3)$ & $2.916(3)$ & $172(2)$ \\
\hline N4A-H4NA $\cdots$ O1A ${ }^{\mathrm{iii}}$ & $0.99(3)$ & $2.21(3)$ & $3.030(3)$ & $140(3)$ \\
\hline
\end{tabular}

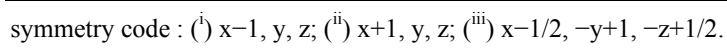

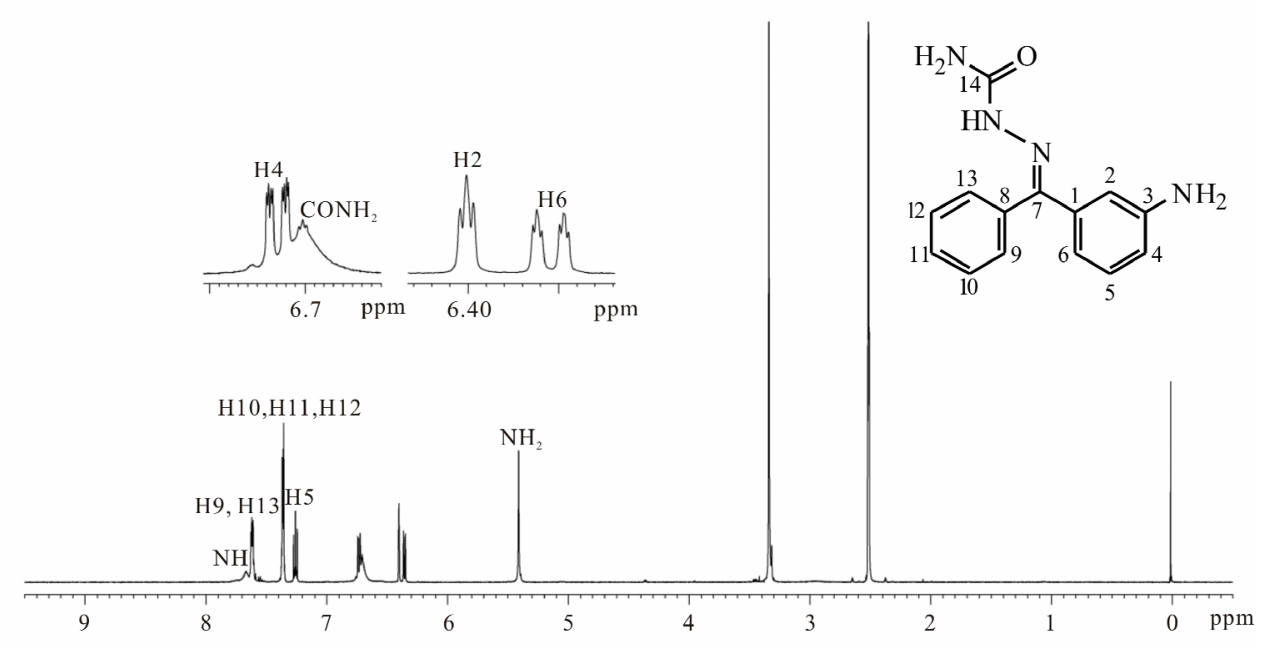

Figure 4. ${ }^{1} \mathrm{H}$-NMR spectrum of APHC.

a multiplet at $\delta 7.61-7.63 \mathrm{ppm}$.

\section{Conclusion}

Semicarbazone substituted 3-aminobenzophenone had been synthesized in good yield. Melting point determination was performed to check the purity of the compound. Results obtained from the elemental, thermal, spectral (FTIR, NMR) and X-ray crystallography had confirmed the proposed structure of the synthesized semicarbazone.

\section{Acknowledgements}

The authors would like to thank Universiti Sains Malaysia, Science Fund Grant No. 1001/PKIMIA/823003 and RU Grant No. 1001/PKIMIA/811196 for the financial support of this work.

\section{REFERENCES}

[1] S. N. Pandeya, P. Yogeeswari and J. P. Stables, "Synthesis and Anticonvulsant Activity of 4-Bromophenyl Substituted Aryl Semicarbazones," European Journal of Medicinal Chemistry, Vol. 35, No. 10, 2000, pp. 879-886. doi:10.1016/S0223-5234(00)01169-7

[2] S. N. Pandeya, V. Mishra, P. N. Singh and D. C. Rupainwar, "Anticonculsant Activity of Thioureido Derivatives of Acetophenone Semicarbazone," Pharmacological Research, Vol. 37, No. 1, 1998, pp. 17-22. doi:10.1006/phrs.1997.0250

[3] T. Hemalatha, P. K. M. Imran, A. Gnanamani and S. Nagarajan, "Synthesis, Antibacterial and Antifungal Activities of Some $N$-nitroso-2,6-diarylpiperidin-4-one Semicarbazones and QSAR Analysis," Nitric Oxide, Vol. 19, No. 4, 2008, pp. 303-311. doi:10.1016/j.niox.2008.07.006

[4] M. J. Ahsan, J. G. Samy, H. Khalilullah and M. S. No- 
mani, "Semicarbazone Analogues: A Mini Review," Der Pharmacia Sinica, Vol. 2, No. 6, 2011, pp. 107-113.

[5] K. Alomar, V. Gaumet, M. Allain, G. Bouet and A. Landreau, "Synthesis, Crystal Structure, Characterization, and Antifungal Activity of 3-Thiophene Aldehyde Semicarbazone (3STCH), 2,3-Thiophene Dicarboxaldehyde Bis (Semicarbazone) $\left(2,3 \mathrm{BSTCH}_{2}\right)$ and Their Nickel (II) Complexes," Journal of Inorganic Biochemistry, Vol. 115, 2012, pp. 36-43. doi:10.1016/j.jinorgbio.2012.04.022

[6] D. S. Raja, N. S. P. Bhuvanesh and K. Natarajan, "Effect of N(4)-Phenyl Substitution in 2-Oxo-1,2-dihydroquinoline-3-carbaldehyde Semicarbazones on the Structure, DNA/Protein Interaction, and Antioxidative and Cytotoxic Activity of $\mathrm{Cu}(\mathrm{II})$ Complexes," Inorganic Chemistry, Vol. 50, No. 24, 2011, pp. 12852-12866. doi:10.1021/ic2020308

[7] S. Shukla, R. S. Srivastava, S. K. Shrivastava, A. Sodhi and P. Kumar, "Synthesis, Molecular Docking and Biological Evaluation of 4-Cycloalkylidineamino 1, 2-Naphthoquinone Semicarbazones as Anticancer agents," Asian Pacific Journal of Tropical Biomedicine, Vol. 2, No. 2, 2012, pp. S1040-S1046. doi:10.1016/S2221-1691(12)60358-X

[8] A. P. Gulya, D. Gynzhu, N. N. Bairak, D. Poirier and V. I. Tsapkov, "Synthesis, Structure and Properties of Complex Compounds of Cobalt, Nickel, Copper and Zinc with 2-Formylpyridine Semicarbazone," Russian Journal of General Chemistry, Vol. 79, No. 7, 2009, pp. 1499-1503. doi:10.1134/S1070363209070160

[9] J. D. Patel and P. J. Shah, "Synthesis, Characterization and Chelating Properties of 4-Butyrylsemicarbazone-1phenyl-3-methyl-2-pyrazolin-5-one," E-Journal of Chemistry, Vol. 7, No. 2, 2010, pp. 357-362.

[10] R. Sharma, S. K. Argawal, S. Rawat and M. Nagar, "Syntheis, Characterization and Antibacterial Activity of Some Transition Metal Cis-3,7-dimethyl-2, 6-octadien- semicarbazone Complexes," Transition Metal Chemistry, Vol. 31, No. 2, 2006, pp. 201-206. doi:10.1007/s11243-005-6374-3

[11] J. Cosier and A. M. Glazer, "A Nitrogen-Gas-Stream Cryostat for General X-ray Diffraction Studies," Journal of Applied Crystallography, Vol. 19, No. 2, 1986, pp. 105-107. doi:10.1107/S0021889886089835

[12] Bruker, “APEX2, SAINT and SADABS," Bruker AXS Inc., Madison, 2009.

[13] G. M. Sheldrick, "A Short History of SHELX," Acta Crystallographica Section A, Vol. 64, No. 1, 2008, pp. 112-122.

[14] J. Bernstein, R. E. Davis, L. Shimoni and N.-L. Chang, "Patterns in Hydrogen Bonding: Functionality and Graph Set Analysis in Crystals," Angewandte Chemie International Edition in English, Vol. 34, No. 15, 1995, pp. 1555-1573. doi:10.1002/anie.199515551

[15] P. Souza, J. M. Merino, V. Fernández and A. Arquero, "Solvent and Metal Ion Effects in Condensation Reactions between Semicarbazides and Pyridine Derivatives and Study of the Complexes with Metal Chlorides," Transition Metal Chemistry, Vol. 17, No. 4, 1992, pp. 338342.

[16] E. N. Nfor, S. N. Esemu, G. A. Ayimele, E. A. Eno, G. E. Iniama and O. E. Offiong, "Synthesis, Stereochemistry and Antimicrobial Activity of Copper (II) and Nickel (II) Complexes of 4-Phenylsemicarbazones," Bulletin of Chemical Society of Ethiopia, Vol. 25, No. 3, 2011, pp. 361370.

[17] U. El-Ayaan, "Transition Metal Complexes of 3-Acetylpyridine $4 \mathrm{~N}$-(2-pyridyl)thiosemicarbazone (HAPS); Structural, Spectroscopic, and Biological Studies," Journal of Coordination Chemistry, Vol. 65, No. 4, 2012, pp. 629642. doi:10.1080/00958972.2012.658381 